\title{
The Impact of Baseline Pain Intensity on the Analgesic Efficacy of Ibuprofen/Caffeine in Patients with Acute Postoperative Dental Pain: Post Hoc Subgroup Analysis of a Randomised Controlled Trial
}

Stefanie Förderreuther - Anette Lampert - Simon Hitier •

Robert Lange $\cdot$ Thomas Weiser

Received: January 31, 2020 / Published online: April 24, 2020

(C) The Author(s) 2020

\section{ABSTRACT}

Introduction: A fixed dose combination (FDC) of ibuprofen $400 \mathrm{mg}$ and caffeine $100 \mathrm{mg}$ has been shown to be more effective than ibuprofen $400 \mathrm{mg}$ alone for the treatment of acute postoperative dental pain in a phase III randomised controlled trial. A post hoc subgroup analysis of the primary data from an active-/placebo-controlled, double-blind, single-centre, parallel-

Enhanced Digital Features To view enhanced digital features for this article go to https://doi.org/10.6084/ m9.figshare.11968512.

S. Förderreuther $(\bowtie)$

Department of Neurology, Ludwig-Maximilians

University, Munich, Germany

e-mail: sfoerder@med.uni-muenchen.de

A. Lampert · T. Weiser

Medical Consumer Health Care, Sanofi-Aventis

Deutschland GmbH, Industriepark Höchst,

Frankfurt, Germany

S. Hitier

Global Medical Consumer Health Care, Sanofi-

Aventis Groupe, Gentilly, France

R. Lange

Global Medical Affairs, Sanofi-Aventis Deutschland

$\mathrm{GmbH}$, Industriepark Höchst, Frankfurt, Germany group study was conducted in patients with moderate or severe baseline pain.

Methods: After dental surgery, patients with moderate or severe pain, which was determined on a 4-point verbal rating scale ('no pain' to 'severe pain'), received a single dose of ibuprofen $400 \mathrm{mg} /$ caffeine $100 \mathrm{mg}$ FDC, ibuprofen $400 \mathrm{mg}$, caffeine $100 \mathrm{mg}$ or placebo. Pain relief (PAR) and pain intensity were assessed $0.25,0.5$, $0.75,1,1.5,2,3,4,5,6,7$ and $8 \mathrm{~h}$ after administration of study medication. The primary study endpoint was the time-weighted sum of PAR and pain intensity difference (PID) from pre-dose baseline, summed for all postdose assessment times from 0 to $8 \mathrm{~h}$ (SPRID $\left.{ }_{0-8 \mathrm{~h}}\right)$. Results: There were 237 patients with moderate pain and 325 with severe pain at baseline. SPRID $_{0-8 \mathrm{~h}}$ was significantly improved with the FDC versus ibuprofen, caffeine and placebo in the moderate and severe pain subgroups. Adjusted mean SPRID $_{0-8 \mathrm{~h}}$ difference for the FDC versus ibuprofen was $18.19(p<0.0001)$ for patients with moderate pain and 7.70 $(p=0.0409)$ for patients with severe pain. With the exception of the 7-h measurement in patients with moderate pain, PID was significantly improved with the FDC versus ibuprofen at all measured time points from 0.5 to $8 \mathrm{~h}$. In the severe pain subgroup, PID was significantly improved for the FDC versus ibuprofen from 0.5 to $3 \mathrm{~h}$ post-dose, but was not significantly different thereafter. 
Conclusion: The enhanced analgesic efficacy of ibuprofen/caffeine FDC versus ibuprofen is most pronounced in patients with moderate intensity pain at baseline, and also evident in patients with severe baseline pain.

Trial Registration: ClinicalTrials.gov identifier, NCT01929031.

\section{PLAIN LANGUAGE SUMMARY}

The non-steroidal anti-inflammatory drug (NSAID) ibuprofen is commonly used to relieve mild to moderate pain. Research suggests that combining ibuprofen with caffeine can increase the analgesic efficacy. Previously, a randomised, double-blind, placebo-controlled study showed that this ibuprofen/caffeine combination was significantly more effective than ibuprofen alone for relieving pain after dental surgery (wisdom tooth removal). Patients in that study had moderate or severe pain, so the researchers conducted another analysis of the study data to investigate how well the ibuprofen/caffeine combination worked in patients with moderate pain and in patients with severe pain. The study found that a single dose of ibuprofen/caffeine was significantly more effective than ibuprofen alone in patients with moderate pain and in those with severe pain. The analgesic effects of ibuprofen/caffeine were more marked in patients with moderate pain than in those with severe pain. This indicates that ibuprofen/caffeine is an effective pain reliever for patients with moderate pain, and to a lesser extent in patients with severe pain.

Keywords: Analgesia; Caffeine; Dental pain; Fixed-dose combination; Ibuprofen; Postoperative pain

\section{Key Summary Points}

Why carry out this study?

While ibuprofen $400 \mathrm{mg}$ is an effective treatment for postoperative dental pain, its efficacy can be enhanced with caffeine. In a randomised, double-blind, placebocontrolled phase III study, the fixed dose combination (FDC) of ibuprofen $400 \mathrm{mg}$ and caffeine $100 \mathrm{mg}$ was more effective than ibuprofen $400 \mathrm{mg}$ alone for the treatment of acute postoperative dental pain.

This post hoc subgroup analysis of the phase III study was performed to assess the efficacy of the ibuprofen/caffeine FDC in those patients with moderate or severe baseline pain.

\section{What was learned from the study?}

The enhanced analgesic efficacy of single dose of ibuprofen $400 \mathrm{mg} / \mathrm{caffeine} 100 \mathrm{mg}$ FDC relative to ibuprofen $400 \mathrm{mg}$ is more pronounced in patients suffering from moderate rather than severe baseline pain.

The advantages of the ibuprofen/caffeine FDC over ibuprofen are even more pronounced for patients who meet the recently approved indication (moderate pain) than the primary study analysis originally suggested.

\section{INTRODUCTION}

The non-steroidal anti-inflammatory drug (NSAID) ibuprofen has been in clinical use since 1968 and is now one of the most widely used over-the-counter (OTC) medications for the management of mild or moderate pain [1-3]. Ibuprofen has a well-proven efficacy and safety profile in the management of acute pain, including postoperative dental pain $[4,5]$, which is a validated model that is widely used to 
investigate analgesics intended for acute pain treatment $[6,7]$.

The analgesic effect of ibuprofen does not increase above what is known as its 'ceiling' dose. Clinical studies have shown that the maximal effective analgesic dose of ibuprofen for acute somatic pain is $400 \mathrm{mg}$ [8-10]. Numerous studies have been undertaken to determine whether adding an adjuvant to the maximal dose of an NSAID or other analgesics (e.g. paracetamol) can overcome the ceiling effect [11]. The most frequently studied adjuvant is caffeine, which has been shown to enhance the antinociceptive effects of NSAIDs, including standard doses of ibuprofen 100-400 mg [2, 12].

Although ibuprofen $400 \mathrm{mg}$ is an effective treatment for postoperative dental pain, with greater efficacy than high doses of other commonly used OTC analgesics [1, 13], its efficacy can be augmented with caffeine [12]. A randomised, double-blind, placebo-controlled study has demonstrated that a fixed dose combination (FDC) of ibuprofen $400 \mathrm{mg}$ and caffeine $100 \mathrm{mg}$ was more effective than ibuprofen $400 \mathrm{mg}$ alone for the treatment of acute postoperative dental pain [12]. Patients in this study had moderate or severe acute pain at the time of analgesic administration [12]. The ibuprofen $400 \mathrm{mg} / \mathrm{caffeine} 100 \mathrm{mg}$ FDC has recently been approved by health authorities in several European countries for the treatment of acute moderate pain.

To better understand the analgesic efficacy of the ibuprofen $400 \mathrm{mg} /$ caffeine $100 \mathrm{mg}$ FDC depending on the pain intensity, we conducted a post hoc subgroup analysis of the primary study efficacy data [12], stratifying patients by baseline pain intensity. Thereby, we were able to separately assess the analgesic effect of the FDC in patients with moderate or severe baseline pain.

\section{METHODS}

The design and conduct of this randomised, double-blind, active- and placebo-controlled, single-centre, parallel-group study have been described in detail previously [12].
The study was conducted in accordance with the Declaration of Helsinki and International Conference on Harmonisation guidelines for Good Clinical Practice [14] and local regulations. The protocol was approved by the institutional review board of the one participating centre. All patients provided written informed consent to participate prior to screening.

\section{Patients}

Briefly, eligible study participants were healthy men and women (aged 18-55 years) scheduled to undergo surgical extraction of three to four impacted third molars with a minimum of two mandibular extractions. Patients qualified for the study when, after dental surgery, their baseline pain intensity (PI) was either 'moderate' or 'severe' on a 4-point verbal rating scale (VRS) with the following options: 'no pain', 'slight pain', 'moderate pain' or 'severe pain'. To be included in the study, patients also needed to be graded 5 or higher on a numerical pain rating scale (NPRS), which ranged from 0 ('no pain') to 10 ('worst possible pain'). Patients were initially asked to verbally rate their pain on the NPRS about $30 \mathrm{~min}$ after the surgical procedure, and periodically thereafter. Patients who did not have 'moderate pain' or 'severe pain' on the VRS and had an NPRS score of less than 5 by $5 \mathrm{~h}$ after the surgical procedure were excluded from the study.

\section{Design}

The study was conducted in two stages, with patients initially receiving a single dose of ibuprofen $400 \mathrm{mg} /$ caffeine $100 \mathrm{mg}$ FDC, ibuprofen $400 \mathrm{mg}$, caffeine $100 \mathrm{mg}$ or placebo (stage 1), followed by multiple doses of ibuprofen/caffeine FDC or ibuprofen over 5 days (stage 2). In this post hoc analysis, only the data from stage 1 of the study were analysed, so only the stage 1 study design is described here. The overall study design is described in the primary publication [12]. For the subgroup analysis included patients were stratified by baseline PI ('moderate' or 'severe' on the VRS). 
During stage 1 of the study, patients were randomised (3:3:1:1) to a single-dose ibuprofen $400 \mathrm{mg} /$ caffeine $100 \mathrm{mg}$ FDC, ibuprofen $400 \mathrm{mg}$, caffeine $100 \mathrm{mg}$ or placebo tablet. The randomisation was generated using a validated system, and patients were randomised in blocks using the baseline VRS ('moderate pain' or 'severe pain') as stratification factor. Investigators and patients were blinded to treatment assignments, and study medication was provided as identically appearing film-coated tablets to ensure blinding. A single-dose of the study medication was administered within $5 \mathrm{~min}$ after the qualifying pain score assessment, and patients remained at the trial site to be observed over an 8-h time period.

Patients who required additional pain relief could receive rescue medication consisting of one to two tablets of either paracetamol $500-1000 \mathrm{mg}$ or paracetamol $500 \mathrm{mg}$ plus hydrocodone $5 \mathrm{mg}$. Patients were encouraged not to take rescue medication within the first $1.5 \mathrm{~h}$ after administration of study medication. Although stage 1 was scheduled to last $8 \mathrm{~h}$, if a patient requested rescue medication or another dose of study medication between 6 and $8 \mathrm{~h}$ post-dose, stage 1 ended at this time.

Patients completed a diary at $0.25,0.5,0.75$, $1,1.5,2,3,4,5,6,7$ and $8 \mathrm{~h}$ after the first dose of study medication, in which they rated their pain relief (PAR) using a 0-4 VRS ( 0 , 'none'; 1 , 'a little'; 2,'some'; 3, 'a lot'; 4, 'complete'), and their PI using the 0-10 NPRS. Pre-dose PI was also assessed in the patient diaries. If a patient required rescue medication or a second dose of study medication before $8 \mathrm{~h}$ post-dose, PAR and PI were assessed before their use. Subsequent PI assessments were still performed after administration of rescue medication or a second dose of study medication.

\section{Endpoints}

The primary study endpoint was the timeweighted sum of PAR and PI difference (PID) from pre-dose baseline PI, summed up for all post-dose assessment times from 0 to $8 \mathrm{~h}$ $\left(\operatorname{SPRID}_{0-8 \mathrm{~h}}\right)$. It was calculated using the following formula: $\operatorname{SPRID}_{0-8 \mathrm{~h}}=0.25 \times\left(\mathrm{PID}_{0.25}+\right.$
$\mathrm{PAR}_{0.25}+\mathrm{PID}_{0.5}+\mathrm{PAR}_{0.5}+\mathrm{PID}_{0.75}+\mathrm{PAR}_{0.75}+$ $\left.\mathrm{PID}_{1}+\mathrm{PAR}_{1}\right)+0.5 \times\left(\mathrm{PID}_{1.5}+\mathrm{PAR}_{1.5}+\mathrm{PID}_{2}\right.$ $\left.+\mathrm{PAR}_{2}\right)+\mathrm{PID}_{3}+\mathrm{PAR}_{3}+\mathrm{PID}_{4}+\mathrm{PAR}_{4}+\mathrm{PID}_{5}$ $+\mathrm{PAR}_{5}+\mathrm{PID}_{6}+\mathrm{PAR}_{6}+\mathrm{PID}_{7}+\mathrm{PAR}_{7}+\mathrm{PID}_{8}+$ $\mathrm{PAR}_{8}$, where PID/PAR $0.25 / 0.5 / 0.75 / 1 / 1.5 / 2 / 3 / 4 / 5 / 6 / 7 /$ ${ }_{8}=$ PID $/$ PAR at times $0.25,0.5,0.75,1,1.5,2,3,4$, $5,6,7$ and $8 \mathrm{~h}$, respectively. SPRID $_{0-2 \mathrm{~h}}$ (timeweighted sum of PAR and PID from pre-dose baseline PI, summed up for the post-dose assessment times from 0 to $2 \mathrm{~h}$ ) was a secondary endpoint. Other endpoints included the time course of PID in the $8 \mathrm{~h}$ after the first dose, and the number of rescue medication doses.

\section{Statistical Analyses}

Endpoints were assessed in the full analysis set (FAS), which included all patients who were randomised and took at least one dose of study medication and provided any post-treatment data for the primary efficacy endpoint. For this post hoc analysis, subgroups were assessed depending on whether baseline PI was 'moderate' or 'severe' on the VRS.

SPRID $_{0-8 \mathrm{~h}}$ and SPRID $_{0-2 \mathrm{~h}}$ were tested using an analysis of covariance, with treatment as fixed effect and the pre-dose baseline pain intensity measured on the 0-4 VRS as a categorical covariate. In these analyses, assessments of PAR or PI completed after administration of rescue medication or a second dose of study medication occurring before $8 \mathrm{~h}$ post-dose were considered missing. The last assessment performed before administration of rescue medication or a second dose of study medication was carried forward to replace observations up to $8 \mathrm{~h}$. If recording of PAR or PI had stopped despite no rescue medication or a second dose of study medication being administered within the initial 8-h post-dose period, last observation carried forward (LOCF) was used. Any other missing PAR or PI data were interpolated from the previous and next recorded observations.

PID at each post-dose time point up to $8 \mathrm{~h}$ was analysed using a likelihood-based repeated measures approach, without using LOCF. In these analyses, all available longitudinal PI values were used whether or not the patient had taken rescue medication or the second dose of 
study medication. There was no imputation of missing values. PID means were adjusted for the continuous covariate of baseline PI (NPRS).

The use of rescue medication was assessed using Yates' continuity-corrected chi-square test for contingency table.

All statistical tests to evaluate differences between the treatment subgroups were carried out using a 2-sided significance threshold alpha of $5 \%$.

\section{RESULTS}

\section{Patient Disposition}

Overall, 748 patients were enrolled in the study, and 562 were randomised and treated in stage 1 (Fig. 1). Of these patients, 237 (42.2\%) had moderate pain (mean NPRS score of 6.8) and $325(57.8 \%)$ had severe pain (mean NPRS score of 8.4) at baseline (Table 1). Patients were aged $18-27$ years. The group with severe pain contained a slightly higher proportion of women than the group with moderate pain $(66.2 \%$ versus $60.3 \%$ ). Demographic characteristics were well balanced across the moderate and severe pain treatment subgroups. Nine patients discontinued the study as a result of adverse events $(N=5)$, non-compliance with protocol $(N=2)$ or other reasons $(N=2)$.

\section{Efficacy}

\section{Pain Reduction}

On the basis of the primary endpoint of adjusted SPRID $_{0-8 \mathrm{~h}}$, the ibuprofen/caffeine FDC was significantly more effective than individual monotherapies and placebo in patients with moderate or severe pain at baseline (Table 2). In patients with moderate pain at baseline, the ibuprofen/caffeine FDC was 52.3\% more effective than ibuprofen in reducing pain over the first $8 \mathrm{~h}$ after drug administration (adjusted mean SPRID $_{0-8 \mathrm{~h}}$ difference of 18.19; $p<0.0001)$. The $17.3 \%$ increase in efficacy with ibuprofen/caffeine FDC compared with ibuprofen was less marked, but still significant in patients with severe pain at baseline (adjusted mean SPRID $_{0-8 \mathrm{~h}}$ difference of 7.70; $p=0.0409$ ). The SPRID $_{0-8 \mathrm{~h}}$ placebo effect (adjusted mean \pm standard error $[\mathrm{SE}]$ ) was numerically highest in patients with severe pain at baseline $(15.07 \pm 4.59$ versus $4.94 \pm 5.45$ for patients with moderate pain), and the adjusted mean $( \pm \mathrm{SE}) \quad$ difference between the

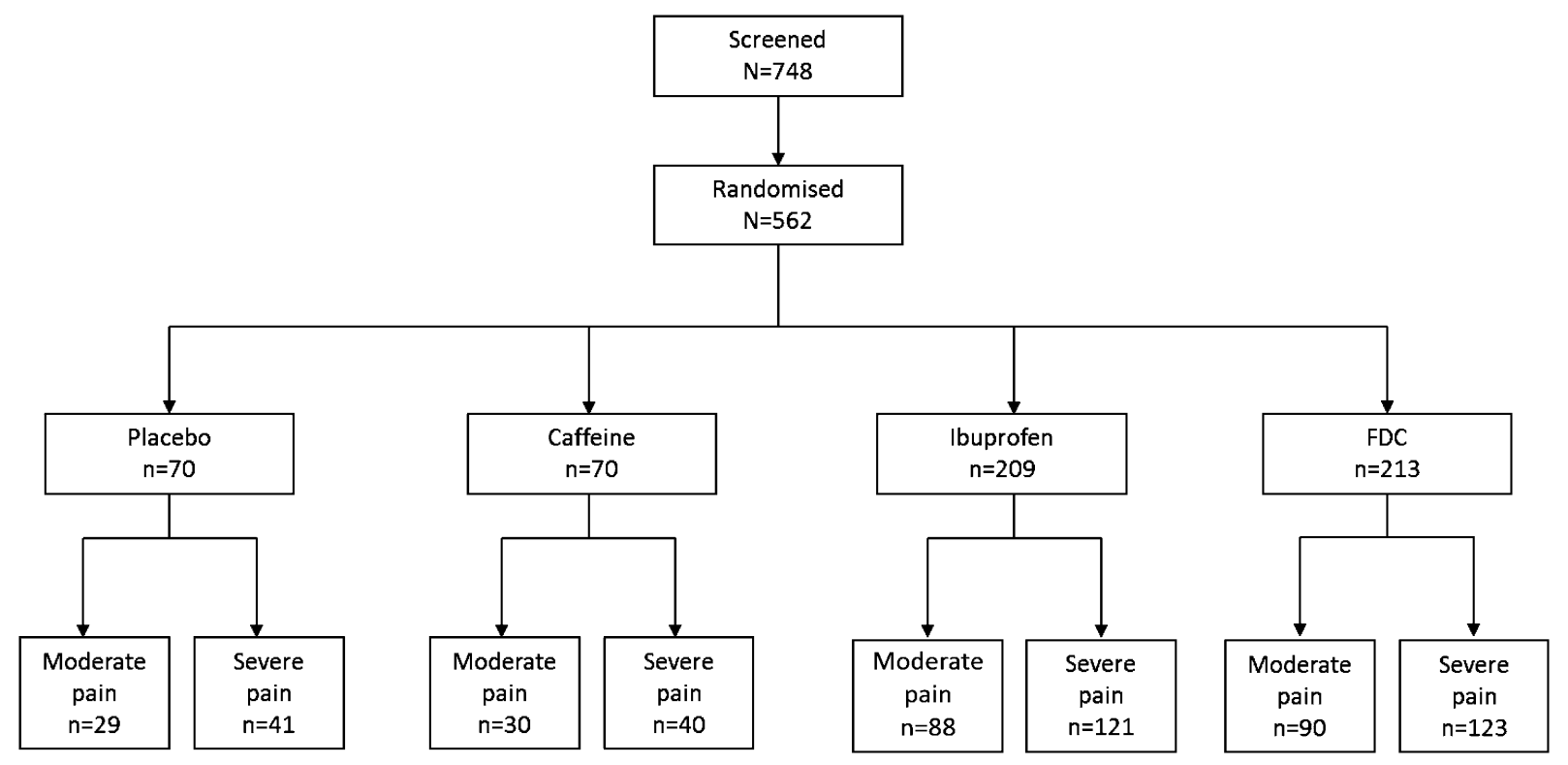

Fig. 1 Disposition of patients. FDC fixed dose combination of ibuprofen $400 \mathrm{mg}$ and caffeine $100 \mathrm{mg}$ 
Table 1 Demographic and other baseline characteristics in the subgroups of patients with moderate or severe pain at baseline

\begin{tabular}{|c|c|c|}
\hline & $\begin{array}{l}\text { Moderate } \\
\text { pain } \\
N=237\end{array}$ & $\begin{array}{l}\text { Severe pain } \\
N=325\end{array}$ \\
\hline \multicolumn{3}{|l|}{ Sex, $n(\%)$} \\
\hline Female & $143(60.3)$ & $215(66.2)$ \\
\hline Male & $94(39.7)$ & $110(33.8)$ \\
\hline \multicolumn{3}{|l|}{ Race, $n(\%)$} \\
\hline White & $226(95.4)$ & $309(95.1)$ \\
\hline Asian & $5(2.1)$ & $7(2.2)$ \\
\hline $\begin{array}{l}\text { Hawaiian/Pacific } \\
\text { Islander }\end{array}$ & $3(1.3)$ & $2(0.6)$ \\
\hline $\begin{array}{l}\text { Native American/ } \\
\text { Alaskan }\end{array}$ & $2(0.8)$ & $2(0.6)$ \\
\hline Black & $1(0.4)$ & $5(1.5)$ \\
\hline \multicolumn{3}{|l|}{ Ethnicity, $n$ (\%) } \\
\hline Not Hispanic/Latino & $213(89.9)$ & $289(88.9)$ \\
\hline Hispanic/Latino & $24(10.1)$ & $36(11.1)$ \\
\hline \multicolumn{3}{|l|}{ Age, years } \\
\hline Mean (SD) & $19.3(1.8)$ & $19.6(2.0)$ \\
\hline Range & $18.0-27.0$ & $18.0-27.0$ \\
\hline \multicolumn{3}{|l|}{ Baseline PI, 0-10 NPRS } \\
\hline Mean (SD) & $6.8(0.6)$ & $8.4(0.8)$ \\
\hline Range & $5.0-8.0$ & $7.0-10.0$ \\
\hline
\end{tabular}

NPRS numerical pain rating scale, $P I$ pain intensity, $S D$ standard deviation

ibuprofen/caffeine FDC and placebo was 48.05 $( \pm 6.27)$ for patients with moderate baseline pain and $37.21( \pm 5.29)$ for patients with severe pain $(p<0.0001$ for both differences).

Early pain relief based on the $\operatorname{SPRID}_{0-2 h}$ endpoint exhibited a similar pattern to SPRID $_{0-8 \mathrm{~h}}$ (Table 2). The ibuprofen/caffeine FDC was $66.9 \%$ more effective than ibuprofen in the group with moderate pain at baseline (adjusted mean SPRID ${ }_{0-2 \mathrm{~h}}$ difference of $4.33 ; p<0.0001$ ), and $41.1 \%$ more effective in the group with severe pain at baseline (adjusted mean SPRID $_{0-2 \mathrm{~h}}$ difference of $3.05 ; p<0.0001$ ). The SPRID $_{0-2 \mathrm{~h}}$ placebo effect (adjusted mean $\pm \mathrm{SE}$ ) was $0.63 \pm 0.75$ for patients with moderate baseline pain and $3.14 \pm 0.92$ for patients with severe pain. Adjusted mean $( \pm$ SE) difference between the ibuprofen/caffeine FDC and placebo was $10.18( \pm 1.25)$ for patients with moderate pain and $7.34( \pm 1.06)$ for patients with severe pain at baseline $(p<0.0001$ for both groups).

\section{Pain Intensity Difference}

With the exception of the 7-h post-dose PID measurement, the ibuprofen/caffeine FDC was significantly more effective than ibuprofen at each measured PID time point from 0.5 to $8 \mathrm{~h}$ post-dose in the group of patients with moderate pain (Fig. 2a). In the group with severe pain, PID was significantly improved for ibuprofen/caffeine FDC versus ibuprofen at all time points between 0.5 and $3 \mathrm{~h}$ post-dose, but was not significantly different thereafter (Fig. 2b).

\section{Rescue Medication}

Rescue medication was required after a single dose of ibuprofen/caffeine FDC by $16.0 \%$ of patients overall, $8.9 \%$ of those with moderate baseline pain and $21.1 \%$ of those with severe baseline pain (Fig. 3). Compared with ibuprofen/caffeine, significantly more patients used rescue medication after single-dose ibuprofen (32.5\% of patients, $p=0.0001)$, caffeine $(64.3 \%$ of patients, $p<0.0001)$ or placebo $(75.7 \%$, $p<0.0001)$. For patients with moderate baseline pain, significantly higher proportions of patients who received placebo, caffeine or ibuprofen required rescue medication compared with those treated with ibuprofen/caffeine FDC $(p<0.0001$; Fig. 3$)$. For patients with severe baseline pain, rescue medication use was not significantly different between the ibuprofen/caffeine FDC and ibuprofen treatment groups $(p=0.0935)$, but it was significantly lower in the FDC treatment group than in the groups receiving placebo or caffeine $(p<0.0001$; Fig. 3). 
Table 2 Pain relief in the first $8 \mathrm{~h}$ (primary endpoint) and $2 \mathrm{~h}$ (secondary endpoint) after study drug administration

\begin{tabular}{|c|c|c|c|c|c|c|c|c|}
\hline & \multicolumn{4}{|c|}{ Moderate pain at baseline } & \multicolumn{4}{|c|}{ Severe pain at baseline } \\
\hline & $\begin{array}{l}\text { Placebo } \\
(n=29)\end{array}$ & $\begin{array}{l}\text { Caffeine } \\
(n=30)\end{array}$ & $\begin{array}{l}\text { Ibuprofen } \\
(n=88)\end{array}$ & $\begin{array}{l}\text { FDC } \\
(n=90)\end{array}$ & $\begin{array}{l}\text { Placebo } \\
(n=41)\end{array}$ & $\begin{array}{l}\text { Caffeine } \\
(n=40)\end{array}$ & $\begin{array}{l}\text { Ibuprofen } \\
(n=121)\end{array}$ & $\begin{array}{l}\text { FDC } \\
(n=123)\end{array}$ \\
\hline \multicolumn{9}{|l|}{$\mathrm{SPRID}_{0-8 \mathrm{~h}}$} \\
\hline Adjusted mean (SE) & $\begin{array}{l}4.94 \\
\quad(5.45)\end{array}$ & $\begin{array}{l}20.27 \\
\quad(5.36)\end{array}$ & $\begin{array}{l}34.80 \\
(3.13)\end{array}$ & $\begin{array}{l}52.99 \\
\quad(3.10)\end{array}$ & $\begin{array}{l}15.07 \\
(4.59)\end{array}$ & $\begin{array}{l}12.96 \\
(4.64)\end{array}$ & $\begin{array}{l}44.58 \\
\quad(2.67)\end{array}$ & $\begin{array}{l}52.28 \\
(2.65)\end{array}$ \\
\hline $95 \% \mathrm{CI}$ & $\begin{array}{l}-5.77, \\
15.65\end{array}$ & $\begin{array}{l}9.74 \\
30.80\end{array}$ & $\begin{array}{l}28.65 \\
40.94\end{array}$ & $\begin{array}{l}46.91, \\
59.07\end{array}$ & $\begin{array}{l}6.06 \\
24.07\end{array}$ & $\begin{array}{l}3.84, \\
22.07\end{array}$ & $\begin{array}{l}39.33 \\
49.82\end{array}$ & $\begin{array}{l}47.08, \\
57.48\end{array}$ \\
\hline $\begin{array}{l}\text { Adjusted mean } \\
\text { difference vs FDC } \\
(\mathrm{SE})^{\mathrm{a}}\end{array}$ & $\begin{array}{l}48.05 \\
\quad(6.27)\end{array}$ & $\begin{array}{l}32.72 \\
(6.19)\end{array}$ & $\begin{array}{l}18.19 \\
(4.40)\end{array}$ & & $\begin{array}{l}37.21 \\
\quad(5.29)\end{array}$ & $\begin{array}{l}39.32 \\
(5.34)\end{array}$ & $7.70(3.76)$ & \\
\hline $95 \% \mathrm{CI}$ & $\begin{array}{l}35.74 \\
60.36\end{array}$ & $\begin{array}{l}20.57, \\
44.88\end{array}$ & $9.55,26.84$ & & $\begin{array}{l}26.81, \\
\quad 47.61\end{array}$ & $\begin{array}{l}28.83 \\
49.82\end{array}$ & $0.32,15.09$ & \\
\hline$p$ value & $<0.0001$ & $<0.0001$ & $<0.0001$ & & $<0.0001$ & $<0.0001$ & 0.0409 & \\
\hline \multicolumn{9}{|l|}{$\mathrm{SPRID}_{0-2 \mathrm{~h}}$} \\
\hline Adjusted mean (SE) & $\begin{array}{l}0.63 \\
\quad(1.09)\end{array}$ & $\begin{array}{l}2.93 \\
\quad(1.07)\end{array}$ & $6.48(0.63)$ & $\begin{array}{l}10.81 \\
\quad(0.62)\end{array}$ & $\begin{array}{l}3.14 \\
\quad(0.92)\end{array}$ & $\begin{array}{l}2.43 \\
\quad(0.93)\end{array}$ & $7.43(0.53)$ & $\begin{array}{l}10.48 \\
(0.53)\end{array}$ \\
\hline $95 \% \mathrm{CI}$ & $\begin{array}{r}-1.51 \\
2.77\end{array}$ & $0.83,5.04$ & $5.25,7.71$ & $\begin{array}{l}9.60, \\
12.03\end{array}$ & $1.34,4.94$ & $0.61,4.25$ & $6.38,8.48$ & $\begin{array}{l}9.44, \\
11.52\end{array}$ \\
\hline $\begin{array}{l}\text { Adjusted mean } \\
\text { difference vs FDC } \\
(\mathrm{SE})^{*}\end{array}$ & $\begin{array}{l}10.18 \\
(1.25)\end{array}$ & $\begin{array}{l}7.88 \\
\quad(1.24)\end{array}$ & $4.33(0.88)$ & & $\begin{array}{l}7.34 \\
\quad(1.06)\end{array}$ & $\begin{array}{l}8.05 \\
\quad(1.07)\end{array}$ & $3.05(0.75)$ & \\
\hline $95 \% \mathrm{CI}$ & $\begin{array}{l}7.72, \\
12.64\end{array}$ & $\begin{array}{l}5.45 \\
10.31\end{array}$ & $2.61,6.06$ & & $5.27,9.42$ & $\begin{array}{l}5.95 \\
10.15\end{array}$ & $1.58,4.53$ & \\
\hline$p$ value & $<0.0001$ & $<0.0001$ & $<0.0001$ & & $<0.0001$ & $<0.0001$ & $<0.0001$ & \\
\hline
\end{tabular}

$C I$ confidence interval, $S E$ standard error, SPRID weighted sum of the pain relief intensity differences

${ }^{a}$ A positive result for the treatment comparison favours the FDC combination

\section{DISCUSSION}

This post hoc subgroup analysis showed that a single dose of ibuprofen $400 \mathrm{mg} /$ caffeine $100 \mathrm{mg}$ FDC was significantly more effective than ibuprofen $400 \mathrm{mg}$ for the management of moderate acute pain, as well as severe acute pain, after dental surgery. For patients with severe pain, PID measurements indicated that the ibuprofen/caffeine FDC provided more effective pain relief than ibuprofen for the first 0.5 to $3 \mathrm{~h}$ post-dose, whereas the efficacy extended for $8 \mathrm{~h}$ in patients with moderate intensity pain.

The results of this subgroup analysis are consistent with the findings of the primary phase III study analysis, in which the ibuprofen/caffeine FDC significantly reduced pain compared with both ibuprofen and placebo [12]. However, some interesting differences between moderate and severe pain were observed relative to the primary analysis findings. In the overall population of study, the FDC was $30.0 \%$ more effective than ibuprofen on the basis of the primary endpoint of 

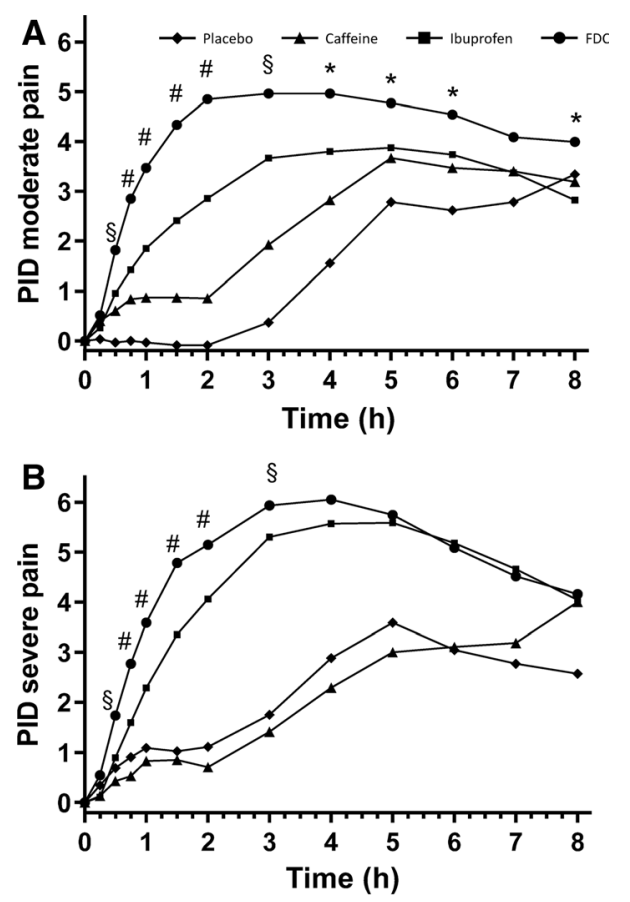

Fig. 2 Adjusted mean pain intensity difference (PID) over time, stratified by baseline pain: a moderate pain and b severe pain. ${ }^{*} p<0.05,{ }^{\$} p<0.001,{ }^{*} p<0.0001$ FDC compared with ibuprofen. FDC fixed dose combination of ibuprofen $400 \mathrm{mg}$ and caffeine $100 \mathrm{mg}$
SPRID $_{0-8 \mathrm{~h}}$ [12]. The current subgroup analysis indicates that much of this effect can be attributed to the efficacy of the ibuprofen/caffeine FDC in the cohort of patients with moderate pain, since the FDC resulted in 52.3\% better efficacy than ibuprofen in this patient subgroup compared with a SPRID $_{0-8 \mathrm{~h}}$ improvement of $17.3 \%$ in patients with severe pain. Similarly, when efficacy was assessed using the SPRID $_{0-2 \mathrm{~h}}$ endpoint, the ibuprofen/caffeine FDC was $51.1 \%$ more effective than ibuprofen in the overall study population [12], but $66.9 \%$ more effective in the subgroup with moderate pain and $41.1 \%$ more effective in the subgroup with severe pain.

Two rating scales were used to assess the intensity of postoperative pain in this analysis. We used the 0-4 VRS to categorise patients as having moderate or severe pain at baseline, but it is interesting to note that the mean NPRS score was 6.8 in the moderate pain group and 8.4 in the severe pain group. Moderate pain on the VRS corresponds to an NPRS score of 4-6 [15], so our post hoc analysis data showed that patients classified as having 'moderate' pain at baseline had pain that was at the severe end for their category. A contributing factor to this observation was that, as well as having

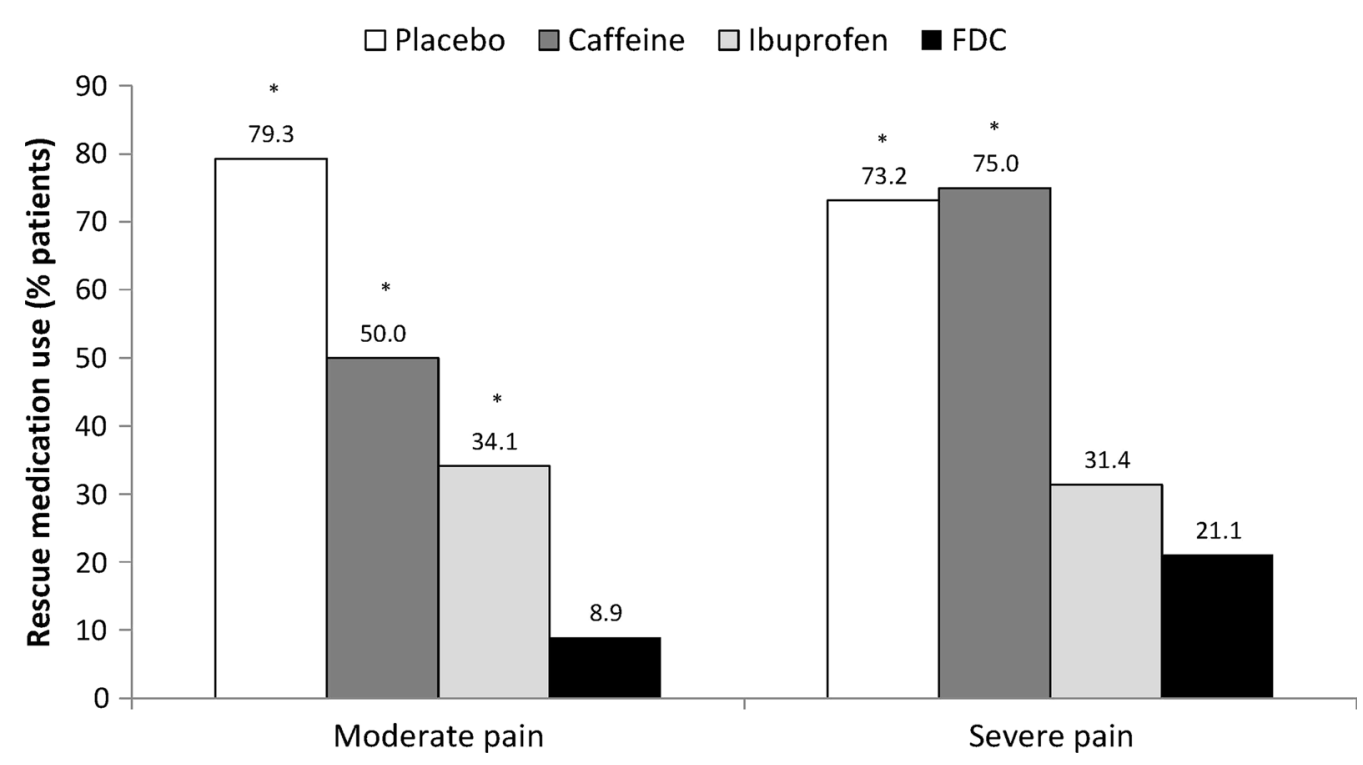

Fig. 3 Rescue medication use during stage $1 .{ }^{*} p<0.0001$ versus FDC. FDC fixed dose combination of ibuprofen $400 \mathrm{mg}$ and caffeine $100 \mathrm{mg}$ 
moderate or severe baseline pain on the VRS, patients needed a baseline NPRS score of at least 5 to be eligible for inclusion in the study, as an NPRS score of at least 5 on a 10-point NPRS (or equivalent) is associated with increased assay sensitivity in chronic pain clinical trials [16]. The NPRS has been shown to result in significantly higher baseline scores than other pain rating scales, including the VRS [17]. It is apparent that there was a clinically relevant difference in pain between the moderate and severe pain subgroups (NPRS difference 1.6), according to the validated minimum clinically significant difference for the NPRS of 1.3 [18]. In addition, our data suggest that patients in the severe pain subgroup had an intense type of pain (mean NPRS 8.4).

Although not interchangeable, the $0-10$ NPRS and 0-4 VRS are correlated and can be reliably used for assessment of acute postoperative dental pain [17]. However, the 0-4 VRS, which we used to categorise patients into moderate and severe pain subgroups, is generally considered insufficiently sensitive to measure pain relief after dental surgery [19]. The 0-10 NPRS, which we used to evaluate postoperative pain, is a validated scale for the assessment of acute pain [18], correlates with other pain rating scales, including visual analogue scales $[18,19]$, and has greater discriminatory capability than the VRS [20]. The NPRS also has the advantages of being easy to use, and having better compliance and responsiveness than other pain rating tools [20], and is ultimately the preferred rating scale for the evaluation of pain in adults $[15,17]$.

The mechanisms underlying the enhanced analgesic effects of ibuprofen with caffeine are not fully understood [11]. Caffeine itself does not appear to have any major intrinsic antinociceptive properties [21], although it does inhibit adenosine receptors, which may be involved in the processing of pain signals [22]. Several analgesic adjuvant mechanisms of action of caffeine that are based on disruption of normal adenosine signalling have been proposed: blockade of peripheral pro-nociceptive adenosine signalling, and activation of the central pain-suppressing noradenosine pathway; adenosine $\mathrm{A}_{2 \mathrm{a}}$ receptor blockade-induced transcriptional downregulation of cyclooxygenase 2; and relief of inhibitor adenosine actions on central cholinergic nerve terminals $[11,23]$. Caffeine is also regarded as a psychostimulant, so caffeine-induced changes in mood and emotional state may contribute to changes in pain perception $[11,23]$. Another potential contributing factor is caffeine-enhanced local tissue levels of the NSAID, with prolonged $\mathrm{ED}_{50}$ (dose for 50\% efficacy) [21].

Studies in which caffeine was used as an analgesic adjuvant have used doses of between $50 \mathrm{mg}$ and $260 \mathrm{mg}$, with typical doses of 100 or $200 \mathrm{mg}$ [11]. The Cochrane analysis of these studies reported that significant analgesic enhancement was seen when at least $100 \mathrm{mg}$ of caffeine was added to standard doses of common analgesics, with an additional $5-10 \%$ of patients achieving a good level of pain relief [11]. The primary study on which this post hoc subgroup analysis was based was the first to investigate the analgesic adjuvant effect of caffeine $100 \mathrm{mg}$ in combination with ibuprofen $400 \mathrm{mg}$ [12].

Ibuprofen and ibuprofen/caffeine were generally well tolerated in this study [12]. Overall, the number of patients with adverse events was low, with no serious adverse events [12]. The safety profile of the ibuprofen/caffeine FDC in the moderate and severe baseline pain subgroups was consistent with the data from the primary study [12], and with previous reports suggesting a small increase in the risk of AEs with caffeine-containing analgesics [24]. Three patients treated with ibuprofen/caffeine FDC had a total of three adverse events (nausea or headache) that were considered drug-related [12]. Although our analysis revealed that all of these events occurred in patients with severe baseline pain, the proportion of patients with severe baseline pain affected by drug-related adverse events was still low at $2.4 \%$.

Typical limitations of a post hoc analysis apply to our study, including the potential for an inflated type I error due to multiple testing. While this limitation must be borne in mind, most of the differences between treatments in our subgroups were significant with $p$ values less than 0.0001, suggesting that the results are robust. 


\section{CONCLUSIONS}

This post hoc subgroup analysis of a phase III study showed that the enhanced analgesic efficacy of single dose of ibuprofen $400 \mathrm{mg} /$ caffeine $100 \mathrm{mg}$ FDC relative to ibuprofen $400 \mathrm{mg}$ is more pronounced in patients suffering from moderate rather than severe baseline pain. Thus, the advantages of the ibuprofen/caffeine FDC over ibuprofen are even more pronounced for patients who meet the recently approved indication (moderate pain) than the primary study analysis originally suggested. For patients with severe pain who do not experience sufficient relief from the FDC, other treatment options such as weak opioids may be considered in line with the WHO analgesic ladder.

\section{ACKNOWLEDGEMENTS}

Funding. This study was funded by Boehringer Ingelheim Pharma GmbH \& Co. KG, Ingelheim am Rhein, Germany. The rapid service fee and open access fee were funded by Sanofi-Aventis Deutschland GmbH. The consumer healthcare business was transferred from Boehringer Ingelheim to Sanofi effective on January 1st 2017.

Medical Writing Assistance. We would like to thank Joanne Dalton, on behalf of Springer Healthcare Communications, who wrote the first draft of this manuscript. This medical writing assistance was funded by Sanofi-Aventis Deutschland GmbH.

Authorship. All named authors meet the International Committee of Medical Journal Editors (ICMJE) criteria for authorship for this article, take responsibility for the integrity of the work as a whole, and have given their approval for this version to be published.

Authorship Contributions. Stefanie Förderreuther read drafts of the manuscript. Anette Lampert contributed to data interpretation, and read and discussed drafts of the manuscript. Simon Hitier performed some of the analyses, contributed to data interpretation, and read and commented on drafts of the manuscript. Robert Lange led the primary analysis interpretation, contributed to this post hoc analysis and reviewed drafts of the manuscript. Thomas Weiser contributed to data analysis and interpretation, discussion of data and drafting of the manuscript.

Disclosures. Stefanie Förderreuther has received honoraria for consulting and lectures within the past 3 years from Allergan Pharma, Astra Zeneca, Hormosan Pharma, Lilly Germany, Novartis Pharma, Sanofi Aventis and TEVA. Anette Lampert, Simon Hitier, Robert Lange and Thomas Weiser are Sanofi employees.

Compliance with Ethics Guidelines. The study was conducted in accordance with the Declaration of Helsinki and International Conference on Harmonisation guidelines for Good Clinical Practice [14] and local regulations. The protocol was approved by the institutional review board of the one participating centre. All patients provided written informed consent to participate prior to screening.

Data Availability. Qualified researchers may request access to patient level data and related study documents including the clinical study report, study protocol with any amendments, blank case report form, statistical analysis plan, and dataset specifications. Patient level data will be anonymized and study documents will be redacted to protect the privacy of trial participants. Further details on Sanofi's data sharing criteria, eligible studies, and process for requesting access can be found at https://www.clinicalstudydatarequest.com.

Open Access. This article is licensed under a Creative Commons Attribution-NonCommercial 4.0 International License, which permits any non-commercial use, sharing, adaptation, distribution and reproduction in any medium or format, as long as you give appropriate credit to the original author(s) and the source, provide a link to the Creative Commons licence, and indicate if changes were made. The images or 
other third party material in this article are included in the article's Creative Commons licence, unless indicated otherwise in a credit line to the material. If material is not included in the article's Creative Commons licence and your intended use is not permitted by statutory regulation or exceeds the permitted use, you will need to obtain permission directly from the copyright holder. To view a copy of this licence, visit http://creativecommons.org/licenses/bync/4.0/.

\section{REFERENCES}

1. Derry C, Derry S, Moore RA, McQuay HJ. Single dose oral ibuprofen for acute postoperative pain in adults. Cochrane Database Syst Rev. 2009;(3): CD001548.

2. Derry S, Wiffen PJ, Moore RA. Single dose oral ibuprofen plus caffeine for acute postoperative pain in adults. Cochrane Database Syst Rev. 2015;(7): CD011509.

3. Duong M, Salvo F, Pariente A, et al. Usage patterns of 'over-the-counter' vs. prescription-strength nonsteroidal anti-inflammatory drugs in France. $\mathrm{Br}$ J Clin Pharmacol. 2014;77(5):887-95.

4. Barasch A, Safford MM, McNeal SF, et al. Patterns of postoperative pain medication prescribing after invasive dental procedures. Spec Care Dentist. 2011;31(2):53-7.

5. Moore PA, Nahouraii HS, Zovko JG, Wisniewski SR. Dental therapeutic practice patterns in the U.S. II. Analgesics, corticosteroids, and antibiotics. Gen Dent. 2006;54(3):201-7 (quiz 8, 21-2).

6. Cooper SA, Desjardins PJ. The value of the dental impaction pain model in drug development. Methods Mol Biol. 2010;617:175-90.

7. Singla NK, Desjardins PJ, Chang PD. A comparison of the clinical and experimental characteristics of four acute surgical pain models: dental extraction, bunionectomy, joint replacement, and soft tissue surgery. Pain. 2014;155(3):441-56.

8. Kellstein DE, Lipton RB, Geetha R, et al. Evaluation of a novel solubilized formulation of ibuprofen in the treatment of migraine headache: a randomized, double-blind, placebo-controlled, dose-ranging study. Cephalalgia. 2000;20(4):233-43.
9. Laska EM, Sunshine A, Marrero I, et al. The correlation between blood levels of ibuprofen and clinical analgesic response. Clin Pharmacol Ther. 1986;40(1):1-7.

10. Seymour RA, Ward-Booth P, Kelly PJ. Evaluation of different doses of soluble ibuprofen and ibuprofen tablets in postoperative dental pain. $\mathrm{Br} \mathrm{J}$ Oral Maxillofac Surg. 1996;34(1):110-4.

11. Derry CJ, Derry S, Moore RA. Caffeine as an analgesic adjuvant for acute pain in adults. Cochrane Database Syst Rev. 2014;(12):CD009281.

12. Weiser T, Richter E, Hegewisch A, Muse DD, Lange R. Efficacy and safety of a fixed-dose combination of ibuprofen and caffeine in the management of moderate to severe dental pain after third molar extraction. Eur J Pain. 2018;22(1):28-38.

13. Moore RA, Derry S, Aldington D, Wiffen PJ. Single dose oral analgesics for acute postoperative pain in adults-an overview of Cochrane reviews. Cochrane Database Syst Rev. 2015;(9):CD008659.

14. International Council for Harmonisation (ICH). ICH Harmonised Tripartite Guideline: Guideline for Good Clinical Practice E6(R1): International Conference on Harmonisation of Technical Requirements for Registration of Pharmaceuticals for Human Use 1996. 1996. https://apps.who.int/medicinedocs/en/m/ abstract/Js22154en/. Accessed 18 Nov 2019.

15. Sirintawat N, Sawang K, Chaiyasamut T, Wongsirichat N. Pain measurement in oral and maxillofacial surgery. J Dent Anesth Pain Med. 2017;17(4): 253-63.

16. Dworkin RH, Turk DC, Peirce-Sandner S, et al. Considerations for improving assay sensitivity in chronic pain clinical trials: IMMPACT recommendations. Pain. 2012;153(6):1148-58.

17. dos Santos Calderon P, Peixoto RF, Gomes VM, et al. Concordance among different pain scales in patients with dental pain. J Orofac Pain. 2012;26(2): 126-31.

18. Bijur PE, Latimer CT, Gallagher EJ. Validation of a verbally administered numerical rating scale of acute pain for use in the emergency department. Acad Emerg Med. 2003;10(4):390-2.

19. Seymour RA. The use of pain scales in assessing the efficacy of analgesics in post-operative dental pain. Eur J Clin Pharmacol. 1982;23(5):441-4.

20. Hjermstad MJ, Fayers PM, Haugen DF, et al. Studies comparing numerical rating scales, verbal rating scales, and visual analogue scales for assessment of pain intensity in adults: a systematic literature 
review. J Pain Symptom Manage. 2011;41(6): 1073-93.

21. Granados-Soto V, Castaneda-Hernandez G. A review of the pharmacokinetic and pharmacodynamic factors in the potentiation of the antinociceptive effect of nonsteroidal anti-inflammatory drugs by caffeine. J Pharmacol Toxicol Methods. 1999;42(2):67-72.

22. Sawynok J. Methylxanthines and pain. In: Fredholm BB, editor. Handbook of experimental pharmacology. Berlin: Springer; 2011. Vol 200, p. 311-29.

23. Derry S, Wiffen PJ, Moore RA, Bendtsen L. Ibuprofen for acute treatment of episodic tension-type headache in adults. Cochrane Database Syst Rev. 2015;(7):CD011474.

24. Zhang WY. A benefit-risk assessment of caffeine as an analgesic adjuvant. Drug Saf. 2001;24(15): 1127-42. 